\title{
Grid-connected and islanded operation of a hybrid power system
}

\author{
Y. Zhou, J. A. Ferreira, P. Bauer \\ Department of Electrical Power Engineering, Delft University of Technology \\ Mekelweg 4, 2628CD, Delft, the Netherlands \\ Phone: +31-15-27-85744, Fax: +31-15-27-82968 \\ Email: y.zhou@ewi.tudelft.nl,j.a.ferreira@ewi.tudelft.nl,p.bauer@ewi.tudelft.nl
}

\begin{abstract}
Rural area often has only one transmission line in connection with main power grid. The safety of critical load cannot be insured. Instead of adding a second transmission line, distributed generation can be installed. In this paper, a hybrid power system is analyzed. It is composed of solar power, wind farm of doubly fed induction generators (DFIG), pumped storage station, residential load and industry load. Both grid connected operation and islanded operation of this hybrid power system are analyzed. A control strategy is proposed to stabilize this power system under islanded condition without the necessary of central master controller. The water tower with back to back voltage source converter (VSC) is operated as a pumped storage station under islanded situation, which controls the frequency and voltage of the islanded power system. Wind farm, solar power, and load contribute to frequency and voltage control of the hybrid power system.
\end{abstract}

\section{INTRODUCTION}

Distributed generation (DG) is an economic choice for remote areas. Using distributed generators as the main power source has some obvious advantages. Firstly the power loss on the long transmission line is reduced, secondly the reliability of the area is increased without the necessary to build a second transmission line for backup. Among the distributed generation sources, renewable energy source develops fast. Its development is driven by the government policy to reduce the greenhouse gas emissions and conserve fossil fuels.

In this paper, a hybrid power system for rural area is analyzed. It has a solar power system, a small wind farm composed of several DFIGs, a water tower operated as small pumped storage station, residential and industry load, and a long transmission line connected with main power grid. Because of the length and limited capacity of the line, the transmission line's impedance between the hybrid power system and power grid is large. In this weak power grid with low $\mathrm{X} / \mathrm{R}$ ratio, voltage fluctuation may cause coupling effect between active and reactive power. More importantly, the distribution line can be out of service without notice. In this digest, firstly the configuration and parameters of this hybrid power system is given, secondly the issues of concern of safely operation of the system are discussed, and then the possible operation strategies and control methods are proposed, both under grid connected situation and islanding situation, and finally the simulation results in Matlab/Simulink are presented.

\section{CONFIGURATION AND PARAMETERS OF THE HYBRID POWER SYSTEM}

\section{A. Topology of hybrid power system}

The hybrid power system includes a solar power system, a small wind farm composed of DFIGs, a water tower, residential and industry loads. It is connected with main power grid through a long and unreliable transmission line. The topology of this system is shown in Figure 1.

Wind farm and solar power are the main power source, their active and reactive power can be controlled independently by VSCs. They can participate in frequency and voltage controls of the power grid.

The water tower is integrated with the local grid through back to back VSCs. It can be operated either in motor mode or in generator mode. It is thus an energy storage device and can work as a small pumped storage station to balance generation and load. In the autonomous power system of [10] and [11], diesel generator or battery is required to start up the wind turbine. In this paper, the wind turbine can be started by the pumped storage station under islanded condition.

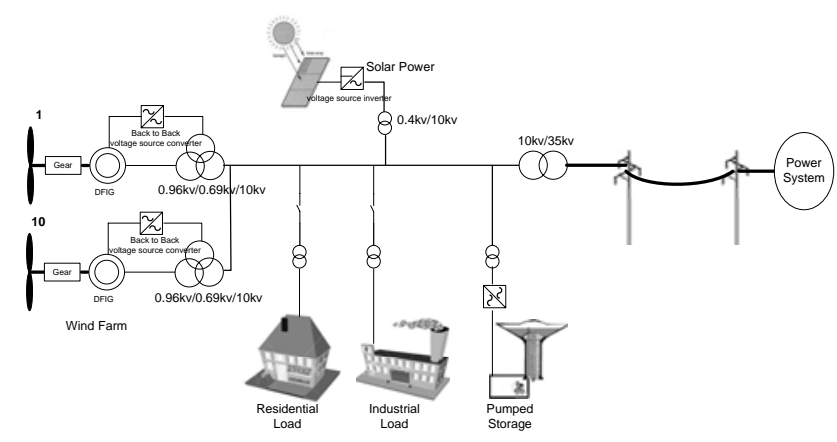

Figure 1 Topology of the hybrid power system

\section{B. Typical parameters of the power system}

Typical parameters of DFIG wind farm, transmission line, transformer and etc are taken from [7], [12] and [13]. 
In Table I, the transformer parameters are referred to the $10 \mathrm{kV}$ side. The DFIG's inertia is calculated by approximate equation in [13].

Table I Case study parameters

\begin{tabular}{|l|c|c|c|c|}
\hline & Type & $\mathrm{R}(\Omega)$ & $\mathrm{L}(\mathrm{H})$ & $\mathrm{C}(\mu \mathrm{F})$ \\
\hline \multirow{2}{*}{ DFIG generator } & Stator & 0.0033 & 0.0047 & \\
\cline { 2 - 5 } & Rotor & 0.0143 & 0.0185 & \\
\hline DFIG transformer & $0.96 / 0.69 / 10 \mathrm{kV}$ & 0.4889 & 0.0118 & \\
\hline Overhead line & $35 \mathrm{kV}$ & $0.17 \Omega / \mathrm{km}$ & $0.0012 \mathrm{H} / \mathrm{km}$ & \\
\hline Cable line & $10 \mathrm{kV}$ & $0.14 \Omega / \mathrm{km}$ & $0.00024 \mathrm{H} / \mathrm{km}$ & $0.42 \mu \mathrm{F} / \mathrm{km}$ \\
\hline Transformer & $10 / 35 \mathrm{kV}$ & 0.664 & 0.208 & \\
\hline \multirow{2}{*}{ DFIG inertia J } & Wind turbine & $2949 \mathrm{~kg} / \mathrm{m} 2$ & & \\
\cline { 2 - 5 } & Generator & $240 \mathrm{~kg} / \mathrm{m} 2$ & & \\
\hline
\end{tabular}

\section{Typical grid connected operation of the power system}

Typical data of power from wind, solar, and consumed load is recorded from [10] and [11]. The site under consideration in [11] is a small village in remote area of India. Here the load and wind power are scaled up to emulate a large town which has heavy industry. The pumped storage station is only working in motor mode for grid connected operation, providing water for drinking or irrigation and keeping water reservoir at a certain level. The power exchange with power grid is then calculated. At point A, the power drawn from grid is at maximum. At point $B$, the power sent to grid is at maximum. If the hybrid power system is disconnected from the power grid when absorbing large amount of power from the grid, then low frequency control is required. If it is disconnected from power grid when sending large amount of active power, then high frequency control is required. In section $\mathrm{V}$, cases of point $\mathrm{A}$ and $\mathrm{B}$ will be studied.

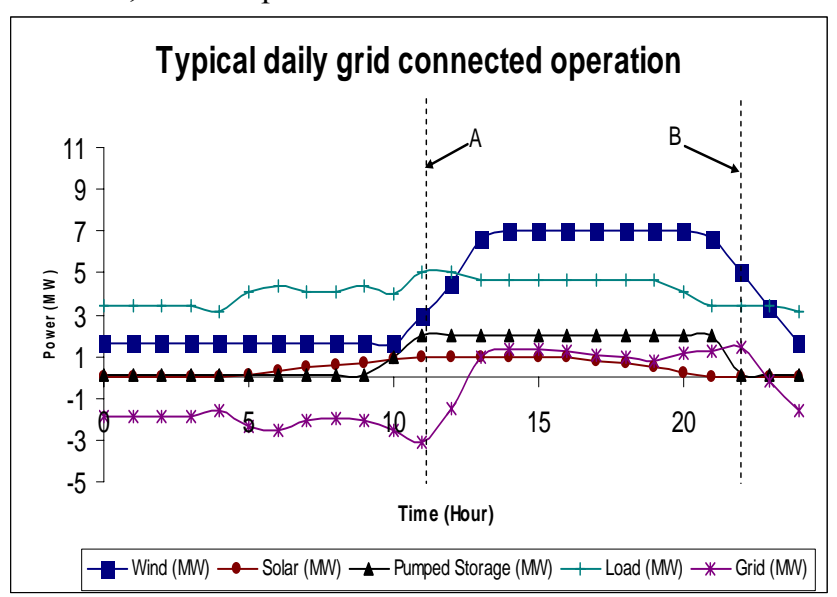

Figure 2 Typical daily operation of the hybrid power system

\section{Simple design of pumped storage station}

The duration time of islanded operation is taken as 24 hours. Under islanded situation, when load is higher than generation such as point A shown in Figure 2, load shedding is used to limit the imbalance between generation and load. However, there are some critical loads which have to be maintained all time, for example, the load of high furnace of steel factory.

The renewable energy sources are working at their maximum power production before grid disconnection. They are not possible to increase their active power for a long time. For example, the kinetic energy in the shaft of variable speed wind turbine can only be used for short term primary frequency support. Normally, it can only last for several tens of seconds. Furthermore, when the kinetic energy of variable speed wind turbine is used for primary frequency control, the rotation speed will deviate from its optimum speed. The power captured from the wind will decrease. Thus from the point of view of long term, it is not good to use kinetic energy of variable speed wind turbine for islanded operation.

Thus the pumped storage station has to provide considerable energy to maintain critical load during islanded situation.

To simplify the design, the critical load is assumed to be 0.5 MW. The renewable sources can provide half of the total required energy. The volume of water tower has to be designed to provide the other half of required energy. The efficiency of pumped storage station is taken as $90 \%$.

The potential energy of water can be calculated as

$\mathrm{P}=\mathrm{m} * \mathrm{~g} * \mathrm{~h}$

The required electrical energy to provide active power of $0.5 \mathrm{MW}$ for 12 hours is $6 \mathrm{MWh}$. It is $2.16^{*} 10^{10}$ Joules. Taking into account of the efficiency, the required potential energy of water is then $2.4^{*} 10^{10}$ Joules. The potential energy of water is both related with the height of water head and the volume of water reservoir. The results are listed as in the following table. The water tower can be placed on a hill to increase water head and decrease the required volume of water reservoir. The water reservoir is assumed to be in cylindrical shape, and its height is taken as $10 \mathrm{~m}$.

Table 2 required volume and height of pumped storage

\begin{tabular}{|c|c|c|c|}
\hline Design number & Water head (m) & volume (liter) & Radius (m) \\
\hline 1 & 20 & $1.22 \mathrm{E}+08$ & 62 \\
\hline 2 & 50 & $4.90 \mathrm{E}+07$ & 39 \\
\hline 3 & 100 & $2.45 \mathrm{E}+07$ & 28 \\
\hline 4 & 150 & $1.63 \mathrm{E}+07$ & 23 \\
\hline 5 & 200 & $1.22 \mathrm{E}+07$ & 20 \\
\hline 6 & 250 & $9.80 \mathrm{E}+6$ & 18 \\
\hline
\end{tabular}

An existing design of water Tower with a capacity of $1.2 * 10^{7}$ liters is found through internet. Its water head is 52 meter. If this water tower is placed on a hill of 150 meter, then it can provide enough energy for the islanded operation of this hybrid power system. 


\section{PROBLEM IDENFICATION OF THE HYBRID POWER SYSTEM}

Although this hybrid power system has many advantages such as reduced power loss and high reliability, it has to face challenges of some new control problems. The control problems include how to detect system separation fast and accurately, how to control several DFIGs and VSCs in parallel operation in a very weak power grid, how to control DFIGs and VSCs in islanded power system to stabilize frequency and voltage without the necessary of centralized controller, how the controllers of DG units can be transferred through grid connected operation to islanding operation and vice versa seamlessly in order to protect the critical load, and what are the influences of different load characteristics. In the following sections, these questions will be discussed in more detail, and then a proper control strategy will be proposed.

\section{A. System separation detection}

If the controllers of DG units under grid connected and islanded operation are quite different, then signals are required to determine the states of the power system and switch the controller between grid connected mode and islanded mode. Literature often suggests that the status of the circuit breaker is not a reliable signal for indication of system separation. The phase angle difference between local power grid and main power system is adopted as the indication of system separation [3], [5]. However, this method requires a central supervision system and continuous communication between central supervision system and DG units.

If controllers of DG units do not have any difference between grid connected and islanded operation, then it is not necessary to detect the states of the power system. In [6], a local control method is designed for VSC without the requirement of central supervision system.

\section{B. Grid connected operation}

It is often a challenge to control the voltage profile in distributed grid due to the low $\mathrm{X} / \mathrm{R}$ ratio. The voltage profile is not mainly influenced by the reactive power as the case in high voltage transmission power grid. The active power flow is found to be critical in controlling the voltage profile in distribution power grid [7]. Thus the maximum active power that can be transmitted from or to the power grid through the distribution line is limited, in order to keep the voltage level of the hybrid power system in the allowable range.

In grid connected operation, DG units work in current controlled mode, assuming the grid voltage is more or less constant. However, in a very weak power grid, the terminal voltages of the generator and VSC will fluctuate. The fluctuation of voltage can cause coupling effect between active and reactive power. Phase locked loop is thus necessary to measure the accurate phase angle. With accurate phase angle of the voltage, active and reactive power can be efficiently decoupled.

\section{Islanded operation}

In islanded operation, without a constant voltage source, the current control mode of DG unit of grid-connected operation is not appropriate. Without a reference voltage source, the DG units have to control the voltage and frequency in the power grid by themselves. This is not an easy control task, especially when several generators and VSCs are operated in parallel. The islanding operation of VSCs can be found in literatures [3], [4], [6], and [7]. The control method of single DFIG for stand-alone operation is found in literatures [1] and [2], but this method is not appropriate for controlling multiple DFIGs in one islanded system.

\section{Influences of different kinds of load}

The characteristics of load can have significant influences on the designation of the controller.

The load can be either static load or inertia load. The static load is resistive load whose consumed active power is related with its voltage level. The inertia load is the motor load whose active power is related with its rotating speed. If the islanded system is composed totally of static load, it will be difficult to operate several DG units in parallel. The reason is that both active and reactive power will influence the voltage level. Thus it is not possible to determine the active power imbalance from the frequency deviation, and reactive power imbalance from the voltage deviation.

In [8], it is stated that without enough inertia load, the system is difficult to be stabilized after being disconnected from main power grid.

\section{E. Transfer between grid connected operation and islanded operation}

In order to protect the critical load, the transfer between grid connected operation and islanded operation must be smooth.

If the controllers of DG units in grid connected operation and islanded operation are quite different, then a master central controller and communications between all DG units are required to determine the change of DG units' controller mode. This will increase the cost and decrease the reliability of the system, and has to be avoided if it is possible.

\section{PROPSED CONTROL STRAGETY OF THE HYBRID POWER SYSTEM}

In order to solve those problems discussed in section III, the following control strategy is proposed.

This control strategy is explained in the following figure. 


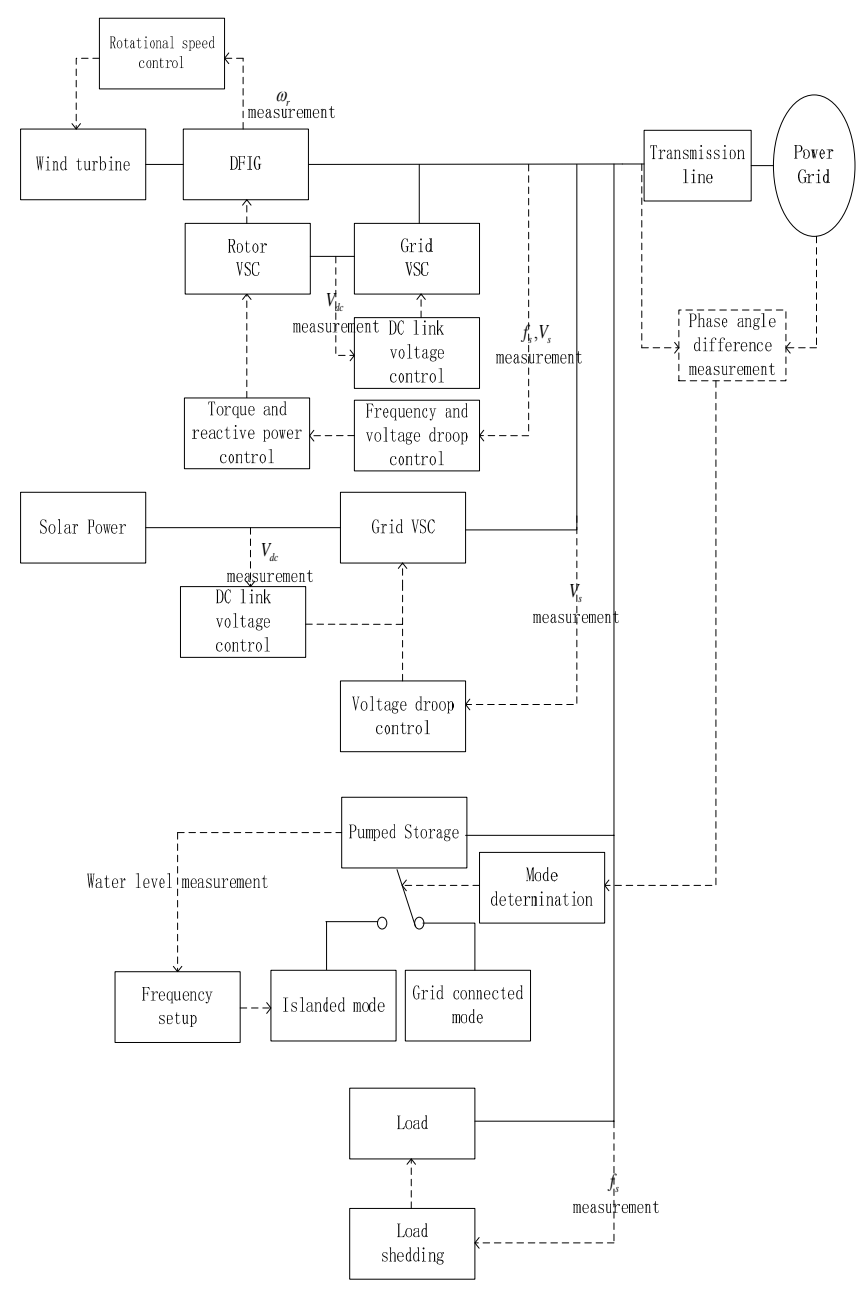

Figure 3 control strategy of the hybrid power system

In Figure 3, the dotted lines are the measurements and control loops, and the solid lines are the electrical connections.

\section{A. Principles of grid connected operation}

The principles for grid connected operation are:

- DFIG wind farm operates under maximum power production mode;

- Solar power system operates under maximum power production mode;

- $\quad$ Pumped storage operates under motor mode, provides water for drinking or irrigation and keep water reservoir at a certain level. Grid side converter controls the DC voltage, generator side converter controls motor power;

- Residential and industrial loads work under maximum;

- The distribution line is in service, transmits power from or to the power grid depending on the balance between power production and consumption in this system;
- Frequency is controlled by the main power grid, while wind farm and solar power can participate in the primary frequency control by using frequency droop control;

- $\quad$ Pumped storage, wind farm and solar power system all participate in the voltage control of the local power grid.

\section{B. Principles of islanded operation}

The principles for islanding operation are:

- Pumped storage station works as a virtual power grid which determines the voltage and frequency of the hybrid power system. Grid side converter controls the AC voltage, generator side converter controls DC voltage;

- $\quad$ DFIG wind farm and solar power system participate in the frequency and voltage control;

- Load shedding is adopted to limit the frequency dip;

- Critical loads must be protected.

\section{Transfer between grid connected operation and islanded operation}

Voltage angle difference between local power system and main power grid is measured. If the angle difference increases to an abnormal value which cannot happen under grid connected operation, then it is determined that the local power system is disconnected from the main power grid. This method is very fast, and can be done in less than one cycle.

A synchronization procedure is required to connect local power system with main power grid. Before synchronization, voltage magnitudes and phase angles of islanded system at point of common coupling (PCC) and grid are measured. The islanded power system at PCC can be controlled by the inverter VSC of pumped storage station. When the magnitude and angle differences between islanded system and main grid approach zero, the synchronization begins, and the hybrid power system is connected with power grid again.

In this control strategy, only one DG unit - the pumped storage station is required to change its control mode. Under grid connected status, the pump storage station is in standard current control mode, while under islanded status, it changes to voltage control mode, and set voltage and frequency of the hybrid power system. This, however, means that the pumped storage station will balance the active power of the hybrid power system. As the volume of the water tower is limited, the total energy that can be used for active power balancing is also limited. Load and DG units can be controlled to help active and reactive power balancing, but they need clear indexes to distinguish between active power imbalance and reactive power imbalance.

As being discussed in section III. D, unlike the main power grid which is composed of synchronous generators, the frequency of the local power system may not change if the 
system is dominated by static load. Then it is not possible to control the load or other DG units for active power and reactive power balancing.

The pumped storage station can change its output - ac voltage's frequency based on its own water level. If the water level is beyond the maximum, its inverter will increase the output ac voltage's frequency. If the water level is less than the minimum, it will decrease the frequency. Then other DG units and load can be controlled by the frequency deviation. When DG units or load take part in the active power balancing, the requirement on the pumped storage station is alleviated.

\section{SIMULATION}

The hybrid power system is modeled in Matlab/Simulink. Dynamic models are developed in the synchronous rotating reference frame in order to improve the simulation speed, because the balanced three phase voltage and current in the synchronous rotating reference frame are DC values at steady state.[15]. Some important control tasks of this hybrid power system are simulated. Simulation results are shown in the following graphs.

\section{A. Transfer between grid connected and islanded operation}

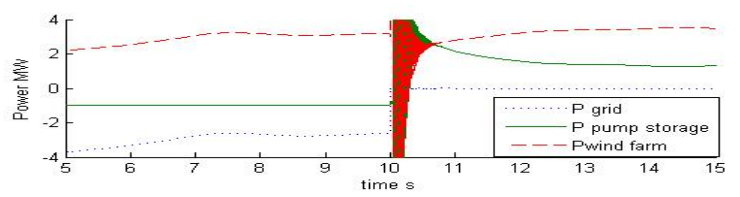

Figure 4 Steady state active power production of the hybrid power system. Dotted line - power flow to the grid, solid line - power production of pumped storage station, and dashed line - power production of wind farm.

During the grid connected period, the pumped storage station works in motor mode, which consumes active power. The imbalance between generation and load in the power system is transmitted to the power grid through the transmission line.

At the $10^{\text {th }}$ second, the transmission line is tripped off. The power flow to the grid immediately drops to zero. Oscillations start in the islanded hybrid power system. After several tens of mille-seconds, the pumped storage station detects the system has been disconnected from the main power grid by measurement of phase angle difference. It then changes from current control mode to voltage control mode. It will work as virtual power grid to balance generation and load.

\section{B. Low frequency control}

When wind speed is low and load is high, the islanded power system may experience generation shortage which has to be balanced by the pumped storage station. As DG units like wind farm and solar power system cannot increase their output power for long time, load shedding is required. The islanded power system's frequency can be controlled by the pumped storage station to enable load shedding.

In Figure 2, at point $\mathrm{A}$, the power absorbed by the hybrid power system is at maximum. Islanded operation at point $\mathrm{A}$ is simulated, and results are shown in Figure 5.
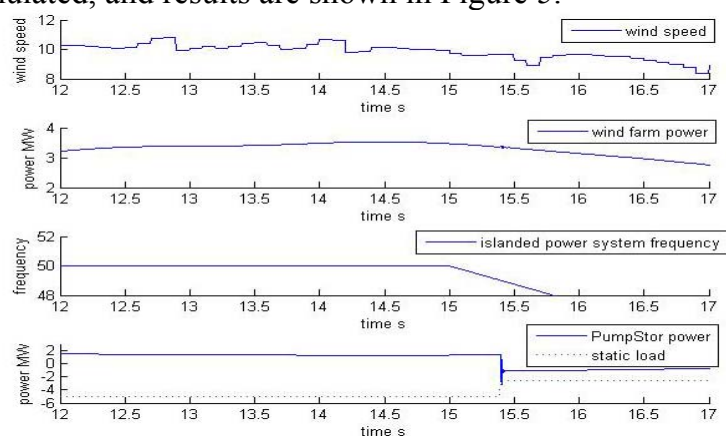

Figure 5 Low frequency control for islanded operation at point $A$ of Figure 2. Graphs from top to bottom are wind speed, power production of wind farm, frequency of islanded power system, power production of pumped storage station and load.

When the islanded system's frequency drops to a low value, the load shedding will begin. After the load shedding, the imbalance between generation and load is limited. Power production of the pumped storage station decreases.

\section{High frequency control}

When wind speed is high and load is low, the islanded power system may have too much generation which has to be absorbed by the pumped storage station. DG units such as wind farm can take part in the high frequency control, by limiting their power production. The islanded power system's frequency can be controlled by the pumped storage station to enable power limitation of DG units.

When the islanded system's frequency increases to a high value, the DFIGs start to limit their active power output by frequency droop control loop in their rotor VSC controller. The imbalance between generation and load is limited, and power absorption of the pumped storage station decreases.
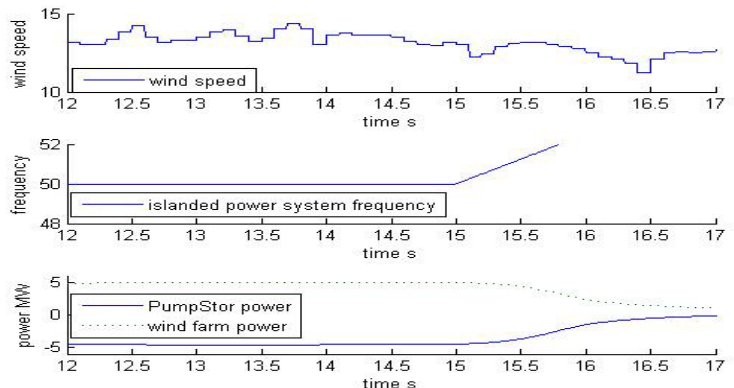

Figure 6 High frequency control for islanded operation at point B of Figure 2. Graphs from top to bottom are wind speed, frequency of islanded power system, power production of pumped storage station and wind farm. 
In Figure 2, at point $B$, the hybrid power system sent maximum power to the power grid. Islanded operation at point $\mathrm{B}$ is simulated, and results are shown in Figure 6.

\section{Voltage control}

All the DG units should contribute to the voltage control by controlling their reactive power output. Otherwise, the pumped storage station will experience too much reactive power flow. Though the reactive power will not affect the stored energy in the water tower, too much reactive power output will increase the ac currents, and can cause over current problems of the VSC.

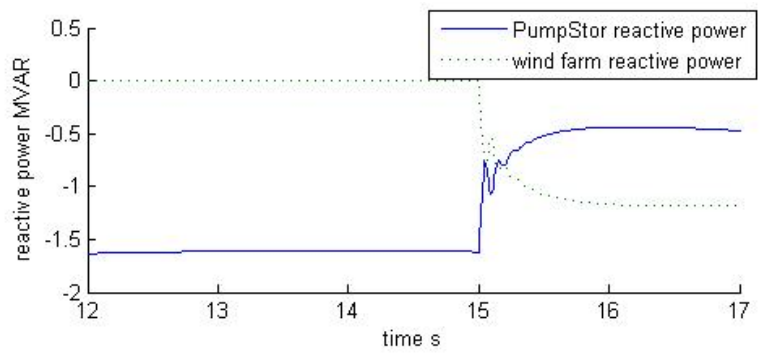

Figure 7 Reactive power production of wind farm and pumped storage station. Solid line - pumped storage station, dotted line - wind farm

Originally, the wind farm controls its reactive power to zero. The ac cables produce large amount of reactive power which has to be absorbed by the pumped storage station.

At $15^{\text {th }}$ second, the wind farm begins its reactive power control through voltage-droop controller. The reactive power which has to be absorbed by the pumped storage station is limited

\section{CONCLUSIONS AND RECOMMENDATIONS}

A hybrid power system for rural area is analyzed. Control strategy is proposed for grid connected and islanded operation. The proposed control strategy functions well even the load is purely static. In this hybrid power system, the water tower with back to back VSCs is worked as pumped storage station. It changes from current control mode to voltage control mode when the hybrid power system is disconnected from the main power grid. It controls the ac voltage and frequency of the power system under islanded operation. DG units contribute to the high frequency control and voltage control. Load shedding is adopted for low frequency control. Simulation results prove that this hybrid power system works fine under grid connected and islanded operation at steady states, though large oscillations appear when the hybrid power system transfers from grid connected operation to islanded operation.

In this paper, it is assumed that the pumped storage station can change from motor mode to generator mode instantaneously. But in reality, several tens of seconds are required for the mode change. The time scale of this mode change is in accordance with the primary frequency control capability of variable speed wind turbine. Thus the kinetic energy of variable speed wind turbine may be used to provide primary frequency during this period.

In future, the transfer between grid connected and islanded operation will be analyzed in more detail, effects of delayed mode change of pumped storage station will be studied, the possibility to control DFIG as synchronous generator in the islanded power system to decouple active power and reactive power will be investigated.

\section{ACKNOWLEDGMENT}

This work is part of the project PhD@Sea, which is substantially funded under the BSIK-program of the Dutch Government and supported by the consortium WE@Sea.

\section{REFERENCES}

[1] R. S. Pena, R. J. Asher, G. M. Clare, "Vector controlled induction machines for stand-alone wind energy applications", Industry Applications Conference, Vol. 3, pp 1409-1415, 2000.

[2] G. Iwanski, W. Koczara, "Island operation of the variable speed induction generator", Power Electronics and Motion Conference, Vol. 2, pp 896-901, 2004.

[3] R. Teodorescu, F. Blaabjerg, "Flexible control of small wind turbines with grid failure detection operating in stand-alone and grid-connected mode", IEEE Transactions on Power Electronics, Vol. 19, Issue 5, pp 1323-1332, 2004.

[4] R. Tirumala, N. Mohan, C. Henze, "Seamless transfer of grid-connected PWM inverters between utility-interactive and stand-alone modes", Applied Power Electronics Conference and Exposition, Vol.2, pp 1081-1086, 2002.

[5] S. Agematsu, S. Imai, R. Tsukui, H. Watanabe, T. Nakamura, and T. Matsushima, "Islanding protection system with active and reactive power balancing control for Tokyo metropolitan power system and actual operational experiences", 7th International Conference on Developments in Power Systems Protection, pp 351-354, 2001.

[6] S. Barsali, M. Ceraolo, P. Pelacchi, D. Poli,, "Control techniques of dispersed generators to improve the continuity of electricity supply", IEEE Power Engineering Society Winter Meeting, Vol. 2, pp 789-794, 2002

[7] J. Morren, "Grid support by power electronic converters of distributed generator units", PhD thesis, Electric Power Engineering, Delft University of Technology, 2006, Netherlands.

[8] P. Sorensen, A. D. Hansen, F. Iov, F. Blaabjerg, "Initial results of local grid control using wind farms with grid support", Technical report, Risø-R-1529, Risø National Laboratory, September, 2005, Denmark,

[9] "Wind power in power systems", John Wiley \& Sons, ISBN: 0-470-85508-8, 2005.

[10] R. Chedid, S. Rahman, "Unit sizing and control of hybrid wind-sloar power systems", IEEE Transactions on Energy Conversion, Vol. 12, No. 1, March, 1997.

[11] P. K. Katti, M. K. Khedkar, "Integrated Operation of Decentralised Resources for Rural Area Power Supply Applications”, 2005 IEEE/PES Transmission and Distribution Conference \& Exhibition: Asia and Pacific Dalian, China, 2005.

[12] "Power system steady state analyze", Chinese Hydro and Electrical Publication, June, 1991.

[13] "Wind energy - the facts, volume 1- technology", www.ewea.org.

[14] C.M. Yam, M. H. Harque, "Dynamic decoupled compensator for UPFC control", International conference on power system technology, Vol. 3 , pp 1482-1487, 2002.

[15] J. Morren, J.T.G. Pierik, S.W.H. de Haan, J. Bozelie, "Grid interaction of offshore wind farms. Part 1. Models for dynamic simulation", Wind Energy, 8 (3): JUL-SEP 2005. 